ENDOSCOPIC SURGERY OF THE POTENTIAL

ANATOMICAL SPACES 


\section{Endoscopic Surgery of the Potential Anatomical Spaces}

Edited by

ATTILIO MARIA FARINON, MD, FACS

Professor of Surgery and Chairman,

Department of Surgery,

University of Rome "Tor Vergata",

Rome, Italy

Assistant Editor:

FRANCESCO RULLI

Department of Surgery,

University of Rome "Tor Vergata",

Rome, Italy

\section{照 Springer}


A C.I.P. Catalogue record for this book is available from the Library of Congress.

ISBN 1-4020-2809-1 (HB)

ISBN 1-4020-2846-6 (e-book)

Published by Springer,

P.O. Box 17, 3300 AA Dordrecht, The Netherlands.

Sold and distributed in North, Central and South America

by Springer,

101 Philip Drive, Norwell, MA 02061, U.S.A.

In all other countries, sold and distributed

by Springer,

P.O. Box 322, 3300 AH Dordrecht, The Netherlands.

Printed on acid-free paper

\author{
All Rights Reserved \\ (C) 2005 Springer \\ No part of this work may be reproduced, stored in a retrieval system, or transmitted \\ in any form or by any means, electronic, mechanical, photocopying, microfilming, recording \\ or otherwise, without written permission from the Publisher, with the exception \\ of any material supplied specifically for the purpose of being entered \\ and executed on a computer system, for exclusive use by the purchaser of the work.
}

Printed in the Netherlands. 
"And it ought to be remebered that there is nothing more difficult to take in hand, more perilous to conduct, or more uncertain in its success, than to take the lead in the introduction of a new order of things. Because the innovator has for enemies all those who have done well under the old conditions, and lukewarm defenders in those who may do well under the new."

N. Machiavelli: The Prince (Chapter VI), 1531 


\section{Contents}

$\begin{array}{ll}\text { List of Contributors } & \text { ix }\end{array}$

Foreword $\quad$ xi

Chapter 1

Antomical Spaces

Richard L. M. Newell

Chapter 2

Radiology of the anatomical compartments

Ettore Squillaci, Rita Cammarata, Giovanni Simonetti

\section{Chapter 3}

Surgical endoscopic access to potential anatomical spaces:

a multidisciplinary issue

Attilio Maria Farinon

\section{Chapter 4}

Technical aspects for access into the neck (minimally invasive video-assisted thyroidectomy-MIVAT)

Paolo Miccoli, Gabriele Materazzi

Chapter 5

Video-assisted thoracoscopic access to the mediastinum

Tommaso Claudio Mineo, Eugenio Pompeo

Chapter 6

Minimally invasive access to the axilla

Gianfranco Tucci, Claudio Amanti

\section{Chapter 7}

Video-assisted approach to the retroperitoneum

Francesco Micali, Flavio Forte

\section{Chapter 8}

Extraperitoneal video-assisted approach to the abdominal aorta John J. Castronuovo 
Total extraperitoneal approach (TEP) for inguinal hernia repair Francesco Mosca, Andrea Pietrabissa, Carlo Moretto

\section{Chapter 10}

Video-assisted access to the subfascial space of the leg

Francesco Rulli, Gabriele Galatà, Michele Grande

\section{Chapter 11}

New Technologies in minimally invasive surgery

Angelo Benevento, Luigi Boni

Author index

Subject index 


\section{List of contributors}

\section{Amanti}

Assistant Professor of Surgery, Department of Surgery, University of Rome "La Sapienza", Rome, Italy

\section{A. Benevento}

Professor of Surgery, University of Insubria, Varese, Italy

\section{Boni}

Assistant Professor of Surgery, Department of Surgery, University of Insubria,

Varese, Italy

\section{R. Cammarata}

Resident, Institute of Radiology, University of Rome "Tor Vergata", Rome, Italy

\section{J. J. Castronuovo}

Clinical Professor of Surgery, University of Medicine and Dentistry, New Jersey Medical School, Newark, Chairman, Division of Vascular Surgery, Morristown Memorial Hospital, Morristown, New Jersey, USA

\section{A. M. Farinon}

Professor of Surgery, Department of Surgery, University of Rome "Tor Vergata", Rome, Italy

\section{F. Forte}

Clinical Researcher in Urology, Department of Surgery, University of Rome "Tor Vergata", Rome, Italy

\section{G. Galatà}

Resident in General Surgery, Department of Surgery, University of Rome "Tor Vergata", Rome, Italy

\section{Grande}

Assistant Professor of Surgery, Department of Surgery, University of Rome "Tor Vergata", Rome, Italy

\section{G. Materazzi}

Clinical Researcher in Surgery, University of Pisa, Pisa, Italy 


\section{F. Micali}

Professor of Urology, Department of Surgery, University of Rome "Tor Vergata", Rome, Italy

\section{P. Miccoli}

Professor of Surgery, University of Pisa, Pisa, Italy

\section{T. C. Mineo}

Professor of Thoracic Surgery, Department of Surgery, University of Rome "Tor Vergata", Rome, Italy

\section{Moretto}

Clinical Researcher in Surgery, University of Pisa, Pisa, Italy

\section{F. Mosca}

Professor of Surgery, University of Pisa, Pisa, Italy

\section{R. Newell}

Clinical Anatomist, Cardiff School of Biosciences, Cardiff University, Cardiff, Wales; Honorary Consultant Orthopaedic Surgeon, Royal Devon and Exeter Healthcare NHS, Trust Exeter, UK

\section{A. Pietrabissa}

Associate Professor of Surgery, University of Pisa, Pisa, Italy

\section{E. Pompeo}

Assistant Professor of Thoracic Surgery, Department of Surgery, University of Rome "Tor Vergata", Rome, Italy

\section{F. Rulli}

Associate Professor of Surgery, Department of Surgery, University of Rome "Tor Vergata", Rome, Italy

\section{G. Simonetti}

Professor of Radiology, Institute of Radiology, University of Rome "Tor Vergata", Rome, Italy

\section{E. Squillaci}

Associate Professor of Radiology, Institute of Radiology, University of Rome

"Tor Vergata", Rome, Italy

\section{G. Tucci}

Associate Professor of Surgery, Department of Surgery, University of Rome

"Tor Vergata", Rome, Italy 


\title{
Foreword
}

"Anatomical potential spaces" is an attractive and no more abstract concept that offers new perspectives to a surgical world that is rapidily changing and becoming more complex.

Powerful new technologies demand our attention and testify that our clinical work and research are deeply influenced by surgical innovations. These latter dramatically modified approaches to treatment through the introduction of entirely new interventions such as minimally invasive surgical procedures, whose real appeal is represented by less invasiveness.

This constantly evolving research environment has gained large acceptance by surgeons accustomed to prompt adaptation to a new trend and inclined to nimble behaviour in the face of innovations. This behaviour, however, requires a rigorous control in order to lead to more reliable, evidence-based practice and to slow or halt the enthusiasm for some harmful or unhelpful treatments, especially if they are proven to be no better than standard procedures.

This particular area of concern has received our attention: to understand whether innovations should be considered as evolutionary variations on a standard procedure or the first stage of what should become recognized as a formal surgical research project.

\author{
ATTILIO MARIA FARINON \\ Professor of General Surgery \\ University of Rome "Tor Vergata"
}

